\title{
El arte y la creatividad en niños y jóvenes: procesos de transformación del espacio escolar y público
}

Díaz Fernández, Adris; Ledesma Gómez, Rodrigo Daniel Gustavo

El arte y la creatividad en niños y jóvenes: procesos de transformación del espacio escolar y público

Revista Educación, vol. 45, núm. 2, 2021

Universidad de Costa Rica, Costa Rica

Disponible en: https://www.redalyc.org/articulo.oa?id=44066178025

DOl: https://doi.org/10.15517/revedu.v45i1.43550

\section{(c) $(1) \Theta$}

Esta obra está bajo una Licencia Creative Commons Atribución-NoComercial-SinDerivar 3.0 Internacional. 
Artículos científicos de experiencia social o didáctica

\section{El arte y la creatividad en niños y jóvenes: procesos de transformación del espacio escolar y público}

Art and Creativity in Children and Youth: Transformation Processes at School and Public Spheres

Adris Diaz Fernández

Universidad de Monterrey, México

adris.diaz@udem.edu

iD https://orcid.org/0000-0003-1944-6136

Rodrigo Daniel Gustavo Ledesma Gómez

Universidad de Monterrey, México

rodrigo.ledesma@udem.edu

(iD https://orcid.org/0000-0002-3141-6565
DOI: https://doi.org/10.15517/revedu.v45i1.43550

Redalyc: https://www.redalyc.org/articulo.oa? $\mathrm{id}=44066178025$

Recepción: 09 Septiembre 2020

Aprobación: 03 Noviembre 2020

\section{Resumen:}

Ante las limitadas observaciones y análisis que se hacen con relación a las acciones artísticas dirigidas a niños, niñas y jóvenes, desarrolladas en las escuelas y fuera de ellas, este texto busca describir el diseño, gestión, implementación e impacto del modelo de intervención artística Leer para Crear, implementado en los espacios públicos con base en el fomento en la lectura y la plástica, a través de la técnica mosaico-Trencadís. El estudio es una investigación cualitativa basada en la entrevista en profundidad, la observación participante, el registro de archivos (fotos y videos) y la triangulación de datos. Esta práctica se realizó con 142 participantes, entre niños, niñas y jóvenes, en el barrio El Nejayote, Monterrey, México, durante el periodo de julio a septiembre de 2017. La experiencia ha sido replicada con éxito en ocho escuelas primarias de la Secretaría de Educación Pública del estado. La información recabada evidencia la efectividad del método de intervención Leer para Crear, al constituir un medio ideal para fomentar el pensamiento creativo e innovador, y el trabajo en equipo, lo cual influye en el desarrollo emocional y en el aprendizaje de las niñas, niños y jóvenes; así como, en el embellecimiento del espacio escolar y público.

Palabras clave: Arte, Educación, Desarrollo creativo y social, Espacios comunitarios.

\section{Abstract:}

Given the limited observations and analysis regarding artistic undertakings aimed at children and youth in schools and the surrounding community, this article describe the design, management, implementation and impact of an artistic intervention model in Mexico known as Reading is Creating (Leer para Crear), which was executed at the community level to promote reading and art using the Trencadis-mosaic technique. The study methodology is based on qualitative research with in-depth interviews, participant observation, file registration (photos and videos) and data triangulation. The activity was conducted with 142 participants, including children and youth in the El Nejayote neighborhood in Monterrey, Mexico from July to September 2017 and was successfully replicated in eight elementary schools pertaining to the Public Education Secretariat. The information gathered reflects the effectiveness of the Reading is Creating intervention model as an ideal way to promote creative and innovative thinking and teamwork which influences learning and emotional development in children and youth, as well as beautifying schools and public areas.

KEYWORDS: Art, Education, Creative and Social Development, Community Spaces.

\section{INTRODUCCIÓN}

El estudio considera trascendental la necesidad de sistematizar y analizar experiencias que evoquen casos de éxitos en el panorama educativo desde las artes y la cultura, binomio que aporta a los niños y niñas competencias blandas (emocionales, motivacionales y valores), además de una responsabilidad social y 
compromiso ante la sociedad, lo que los convierte en ciudadanas y ciudadanos responsables, solidarios, empáticos y proactivos. No es un secreto para nadie que existen infinidad de experiencias que relacionan el arte con la educación, esto por medio de métodos de intervención diferentes que han sido aplicados a lo largo de los años y en diferentes partes del mundo; tendencia que va en alza en los tiempos actuales. En este terreno, desde la mirada cultural, no se le presta mucha atención el documentar y evaluar el impacto de estas prácticas de intervención, brindadas por promotores y gestores culturales; sin embargo, desde la academia, las exposiciones son más evidentes.

Por esta razón, la necesidad de comunicar el proceso y resultados de los proyectos de integración arteeducación ha adquirido mayor importancia desde la cultura. En este trabajo se ofrece un examen detallado de un modelo de intervención educativo- artístico, con base en el fomento de la lectura y la plástica a través de la técnica mosaico-Trencadís (mosaicos rotos), que busca promover la participación de la infancia en la construcción del espacio escolar y público. Luego de haberse consolidado y probado su efectividad en ocho escuelas primarias, ha logrado cruzar el escenario educativo desde su estado físico, para incursionar en la comunidad, al brindar herramientas para su posterior práctica en otros contextos como el comunitario.

Desde una perspectiva histórica, la relación entre arte y educación se ha transformado de acuerdo con las épocas históricas. Por más que esta analogía pase por un proceso de cambio, aún persiste una versión limitada de su empleo en el ámbito educativo. No obstante, es apenas con el surgimiento de la psicología como disciplina que se le otorga valor a la originalidad y a la expresión, aptitudes que fueron tomadas como relevantes por los y las docentes (Efland y Stuhr, 2003).

Jiménez (2011) afirma que:

A partir del siglo XVII, psicólogos y pedagogos ilustres como Juan Amos Commenius, John Lock y J.J. Rousseau, hicieron notar que el arte puede servir como un elemento educativo, destacándose con ello sus dos valores: el artístico-creadoremotivo y el psicopedagógico-expresión-comunicación, insistiendo en la idea de que, siendo medios de comunicación, deben aprenderlos todos, así como se hace con el lenguaje oral y escrito. (p.10)

Pero las inquietantes y favorables transformaciones no se perciben con claridad hasta la primera mitad del siglo XIX, al considerar estos signos artísticos como una forma de "expresión libre, y no como la repetición inútil de cánones estereotipados" (Jiménez, 2011, p.10). Es para ese entonces que queda demostrado que el arte suscita un efecto positivo, pues desarrolla "tanto habilidades sociales, corporales y psicológicas, así como un desarrollo verdadero de la autoestima y el autoconcepto” (García, 2012, párr.45).

De igual manera, para la educación aparecen nuevos elementos relacionados de manera directa con la conducta, con la inserción de la vida cotidiana, con la libertad de expresión, por lo que, de acuerdo con lo anterior, García (2012) menciona que la escuela debe capacitar a los niños y niñas para transformar el mundo en el que viven.

"La educación tiene que ver con el futuro, no con el pasado, y sin embargo es ahí donde nos encontramos" (Gerver, 2010, p. 165). Entonces, aparece el criterio educación tradicional como un freno a estas ideas y la educación emprendedora (Robinson, 2012a), como el antídoto ante todas las limitaciones, normas y regulaciones vigentes. En fin, como una actitud nihilista ante el pensar educativo pasado. La educación emprendedora es

Convertir a los niños y niñas en ciudadanos de primera fila, con un rol participativo en la sociedad desde su entrada en los centros educativos, y actitudes responsables respecto a su contexto y también respecto a los propios sueños y vocaciones (Cros, Forasté, y Masgrau, 2015 p.68).

Checa, Díaz, Guzmán, y Olaya (2017) retoman la idea de Hart (1983) con razón a la oposición que presenta el enfoque tradicional de enseñanza y aprendizaje con relación al cerebro. Al respecto, exponen que su hipótesis era que la enseñanza compatible con el cerebro tendría como resultado un mejor aprendizaje, clima y conducta. Asimismo, declaraban enfáticamente que para que la educación fuera 
realmente "compatible con el cerebro" debía ocurrir un cambio en el paradigma de enseñanza-aprendizaje (p.9).

En los tiempos actuales, tan convulsos y vertiginosos, se necesita de una mirada diferente en la formación de las niñas, niños y jóvenes, en donde, por un lado, se incorporen técnicas didácticas que estén acordes a la fluidez de estos momentos, y por otro, que se busque incorporar otras acciones que ofrezcan una visión actual y real del mundo, que invite a descubrir, entender y solucionar los problemas que irrumpen en el día a día. En este pensar se puede distinguir que el arte y la cultura es un camino ideal para ello: "Cuando la educación se encuentra con el arte y la cultura, se abre una vía que brinda a niños, niñas y jóvenes la posibilidad de desarrollar todo su potencial" (Consejo Nacional de la Cultura y las Artes, 2016, p. 10).

De acuerdo con Berdejo y Urbina (2018), el arte se presenta como un instrumento para la "presentación estética social y su imbricación educativa para la formación de una conciencia social, solidaria y comprometida con los reclamos de carácter popular" (p.8), así como una vía directa para la resolución de los problemas sociales y culturales del entorno.

No se deben olvidar las competencias que expone el Dr. Elliot Eisner (1972) con relación a los aportes que el arte puede brindar a la educación: permite la relación entre elementos y formas, incentiva a una mirada detallada, y, por ende, impulsa la toma de decisiones; estimula tanto el pensamiento divergente como creativo, se es más flexible y realista, y da una mirada estética hacia el mundo.

Confirmar lo expuesto con anterioridad deja entrever la relevancia del arte en la educación, y la necesidad de potenciar al arte en el ámbito educativo y comunitario. También es significativo señalar que

Los espacios para el arte son a la vez, espacios para ser, crear y transformar, son contextos que generan múltiples oportunidades (...) arte y creatividad pueden encontrarse en los espacios recónditos e inesperados y en las actividades cotidianas de la gente común (Elisondo, Donolo y Rinaudo, 2012, p.3).

Se parte de la problemática de que, en los planes curriculares, la educación artística no goza de la notoriedad de las otras materias, y el pensamiento creativo no se fomenta en las edades tempranas, a pesar de ser una competencia de importancia para el desarrollo infantil, ya que contribuye a la exploración y descubrimiento de soluciones nuevas y factibles (González y Segura 2019, citado en Sañudo y Ademar, 2019). Díaz, Figueroa, Bigurra, y Fontecilla (2020) afirman, además, la necesidad de realización o la inclusión de talleres artísticos para desarrollar o fortalecer la creatividad del estudiantado.

Por ello, esta investigación pretende describir el diseño, gestión, implementación e impacto del proyecto educativo-artístico Leerpara Crear en el espacio público a través del arte, en el barrio El Nejayote, Monterrey, México. La experiencia ha sido replicada con éxito en ocho centros escolares del estado. Lo interesante de esta pesquisa es que no se circunscribe únicamente a la labor artística desarrollada en los ocho centros escolares, esto solo se exhibe a manera de vivencia práctica de la metodología de intervención. El estudio evalúa el modelo de intervención educativo-artístico, aplicado en las escuelas, pero en un espacio externo: la comunidad, es decir, en el lugar más íntimo de la ciudad, el barrio.

\section{EL ARTE DEMANDADO POR LA EDUCACIÓN Y LA SOCIEDAD}

En la actualidad, cuando se hace referencia al arte y su relación con la educación, de inmediato el pensamiento se remonta al mundo de la educación artística "limitándose a la producción de beneficios educativos generales y no como forma de producción cultural” (Sánchez, 2010, p.43).

No obstante, "la educación artística interpela y modifica a los sujetos en la construcción de su conocimiento" (Fernández, 2010, p.40), y contribuye al desarrollo de capacidades cognitivas, expresivas y relacionales específicas (Parsons, 2002; Read, 2007; Eisner, 1992; Efland, 2004 citadas en Sánchez, 2010). En este engranaje educación-arte, el arte y la cultura como piedra angular del proceso educativo, ayuda a pensar la vida de manera diferente, ya que convoca a la reflexión crítica y a la transformación de la realidad 
circundante (Eva Morales citado por Santodomingo, 2019). El Secretario General de la Organización de Estados Iberoamericanos para la Educación (OEI), Álvaro Marchesi (2009), menciona la importancia de las artes como espacio de transformación de la dimensión humana (p.7).

Todo lo mencionado demuestra la importancia que, poco a poco, se le ha estado proporcionando al arte en la educación, el propio Marchesi (2009) hace hincapié en que "el aprendizaje y la experiencia del arte en las escuelas y fuera de ellas constituye una de las estrategias más poderosas para la construcción de la ciudadanía" (p.7), esfuerzo que se debe pronunciar desde la política educacional y la formación del docente, ideas que son apoyadas por Fernández, 2009; Sánchez, 2009; Villela, 2009; Martínez, 2009; Giráldez, 2009; Torres, 2009 (citados por Giráldez y Pimentel, 2009).

El actuar diferente es una condición vital para vivir y convivir en el momento presente y desarrollar capacidades creativas y de inclusión social en niños, niñas y jóvenes. Para ello debe considerarse al arte como una "importante oportunidad para ser, crear y transformar la realidad" (Elisondo, Donolo y Rinaudo, 2012, párr.1). Por tal motivo, cada vez se hace más evidente la necesidad de incluir el arte no sólo en las escuelas, sino en toda la sociedad (Palacios, 2006).

En este contexto se pretende, por un lado, que las escuelas deban estar al margen de los problemas de la sociedad y ser además un motor de transformación institucional (Checa et al. 2017), y por otro lado, ser un generador de una cultura escolar propia, donde las artes puedan servir de andamiaje en la construcción de las estructuras afectivas y pedagógicas, que favorecen la transmisión de valores, no como algo impuesto de forma unívoca, sino como piezas integrales para las personas (Gardner, 1994).

En fin, las ideas con relación al arte y la educación han favorecido a que se tome conciencia, gradualmente, de su importancia, y, como expresa Gardner (1994), las personas se verán beneficiadas de la ayuda que pueden recibir cuando aprenden a leer y a escribir en los diversos lenguajes de las artes. (p. 30)

Otro aspecto para destacar en la educación es la necesidad de la vivencia afectiva del niño y la niña con su medio, representado tanto el medio como lo que la niña y niño aportan a través del nivel ya alcanzado (Cabrera y Gallardo, 2013). En esta trama social se apuntan tres componentes claves en la formación: el intelectual, el motivacional y el práctico (Labarrere Reyes y Valdivia Pairol, 2002 citado por Cabrera y Gallardo, 2013).

\section{Lo que hace el arte}

Abad (2012) expone que la irrupción de artistas o docentes a través del arte en el ámbito escolar "significaba una trasgresión en las rutinas para interrumpir la normalidad, buscando el diálogo, la reflexión crítica y la invitación a experimentar, conocer e investigar en los procesos comunitarios" (p.28).

En esta perspectiva, González (2012) enuncia al arte como una manifestación de la expresión y la comunicación humana que produce impacto, experiencia e imaginación en quienes la desarrollan a través del uso de diversos lenguajes o técnicas empleadas en el trabajo creativo. Checa et al. (2017) defienden la idea de que un cambio de actitud hacia el arte proporciona experiencias positivas, tanto cognitivas como afectivas, ya que el solo hecho de contemplar y reflexionar sobre una obra artística se convierte en un medio para descubrir, plantear y resolver los problemas de la vida cotidiana de una manera diferente.

González (2012) además describe que esos problemas "se encuentran en la vida cotidiana del estudiante, en su familia, en la escuela, en la sociedad y el contexto” (p.73). Entonces, no es difícil comprender hasta qué punto el arte es trascendental en la educación y cómo el binomio arte-educación es capaz de transformar el entorno, resolver y aportar soluciones a los problemas que revela la sociedad. Así, todo lo expuesto hasta aquí muestra lo significativo del cambio del paradigma educativo, de una educación tradicional (estática, bañada de verdades absolutas y fragmentada) a una educación emprendedora cargada de cambio, iniciativas, colaboración, de expresiones, sentimientos, emociones y centrada en el alumnado. 
"El cambio de paradigma educacional supone entender la institución artístico-cultural como un espacio situado en el circuito de aprendizaje y de transformación social” (Llevadot y Pagès, 2018, p.122). El impacto está en "propiciar los procesos de creación artística y dejar la técnica y la tecnología sólo como apoyo instrumental” (González, 2012, p. 59).

\section{Restituir el paradigma educativo es una necesidad}

Ante estas condicionantes, se debe destacar que la reforma educativa, con su nueva concepción de Nueva Escuela Mexicana (NEM), ha suscitado centrar una atención especial a las artes, presentado en su Artículo $3^{\circ}$ Constitucional (Subsecretaría de Educación Básica, 2019).

Esta reformulación curricular es un avance de las transformaciones que estos tiempos reclaman. No obstante, queda en la superficie, pues para llevarlo a vía de actuación se necesita de la infraestructura necesaria y del personal capacitado (con los conocimientos de artes) para ello. Cualquier conflicto suscitado en su andar afectaría directamente al estudiantado en su motivación y quizás hasta su propia autoestima. El cambio formulado, acorde a las exigencias actuales, desembocaría en "la formación de personas técnicamente competentes y socialmente comprometidas en la solución de los grandes problemas nacionales y globales, lo que implica fortalecer la formación ciudadana" (Subsecretaría de Educación Básica, 2019, párr.4). El recelo está en su ejecución, aunque el objetivo no es analizar este despliegue de iniciativas educativas, sí se considera que su implementación es un foco de interés que merece mirarse con lupa y con sentido crítico.

\section{La práctica y su visión en la relación arte-educación}

Se puede decir con certeza que el binomio arte-educación es un componente básico en la formación integral de los niños, niñas y jóvenes; para ello se requiere de actitud de apertura, de impulso, motivación y de una sensibilidad a los problemas. En fin, es una elección consciente cargada de significado.

García (2012), basado en lo anterior, explica que la conexión arte-educación no es nada nuevo, que existen experiencias que avalan sus beneficios y aportaciones, tales como la Escuela Nueva, Educación por la Acción y Summerhill, etc., quienes abogaron por la “autoexpresión creativa del niño desde la no intervención”. (párr.4) Por el Contrario, la DBAE (Discipline Based Arts Education) propone que además de motivar y apoyar a la niña y el niño, debe ayudárseles a que, a su nivel, entiendan los conceptos por medio imágenes del arte valoradas culturalmente.

A partir de la década de los ochenta del siglo pasado, en Europa y Estados Unidos, el arte en la escuela adquirió una mayor presencia. Se consideró que el arte daba más oportunidades a los niños y niñas, ya que combina la inteligencia y sensibilidad, reflexión y emoción (Gadamer,1998; Eisner, 1987; Kerlan, 2007). Sin embargo, durante largo tiempo, las políticas culturales y educativas habían aislado al arte de la educación escolar y viceversa, lo que generó barreras en el proceso de aprendizaje y su dimensión creativa, esto convirtió a la escuela en receptora de actividades estandarizadas (Pagès, 2011) "con poco margen de participación y aprendizaje por parte de alumnos y maestros” (Llevadot \& Pagès, 2018, p.122).

Existen muchas experiencias que dan fe de lo valioso que es el arte en la educación. Un ejemplo es el proyecto ConArte Internacional, surgido el año 2013 en Girona, en colaboración con la UNESCO y ConArte México, cuya finalidad era empoderar a jóvenes, niños y niñas a través del arte en las escuelas públicas. El programa bianual de ConArte Internacional Planters buscaba introducir la música, el teatro y la danza en la educación artística en cinco escuelas y tres institutos de Salt, Torroella-L'Estartit y Figueres. Entre sus principales hallazgos destaca la mejora de los aprendizajes generales de los y las participantes. Además, menciona un fuerte impacto directo en el desarrollo de su competencia intercultural y una mejora de la participación en la vida cultural (Gemma 2017). "Se observó además una mejora de los expedientes 
académicos de los estudiantes que participaron en el proyecto en comparación con estudiantes que no participaron" (Gemma, 2017, p.3).

Otra muestra de interés es lo acontecido con Arts Integration del Kennedy Krieger Institute en Baltimore, que se presenta como una metodología de enseñanza en donde los alumnos y alumnas, a través de las expresiones artísticas, demuestran los conocimientos adquiridos, con lo que consiguen de igual forma vincular diferentes áreas del conocimiento al mismo tiempo (Llevadot y Pagès, 2018). Uno de los logros de esta intervención es "que los docentes se adaptan a la forma de aprender de los estudiantes, desarrollan una mayor comprensión y curiosidad intelectual, así como más tolerancia, confianza, motivación y autoexigencia" (Llevadot y Pagès, 2018, p.123).

Si se sigue indagando en el tema, se encontrarán muchos más ejemplos que se muestran como antecedentes concluyentes de que la idea del arte en la educación se fragua como una necesidad, en donde el progreso desde la educación es vital por los beneficios que aporta a las personas involucradas, ya sea para docentes como para el propio alumnado.

En línea con lo que se ha registrado, se encuentra un estudio de un caso singular de integración del arte en educación: arte y escuela del centro de artes contemporáneas ACVIC, el cual surge de la colaboración de una asociación de artistas y creadores - de H. Asociación para las Artes Contemporáneas fundada en 1991 - y de dos administraciones: la local y la autonómica. El centro cultural pertenece a la Red de Centros Territoriales de Artes Visuales de Cataluña cuyo, objetivo, según Llevadot y Pagès, 2018, es:

...presentar una perspectiva integradora entre arte y pedagogía por parte de un equipamiento cultural público, entendiendo que el hecho educativo va más allá de la escuela y que el hecho cultural y artístico no es exclusivo de los museos o centros de arte. (p. 124).

Para 2010, en ACVIC se ponen en funcionamiento unas nuevas metodologías de aprendizaje basadas en la creatividad y consonancia; con esta propuesta para el 2014 - 2015, se incluye el tema de la cuarta edición del proyecto Arte y Escuela. En este entorno educativo es que se desarrolla el estudio de caso con 30 centros educativos, 35 proyectos y 3,200 alumnas y alumnos implicados. A partir de un eje temático común —en este caso la luz-, las personas asesoras de arte y docentes compartieron e intercambiaron ideas y recursos mediante el vínculo entre prácticas artísticas contemporáneas y educativas durante todo un curso escolar.

Los resultados de esta intervención arrojaron niveles altos de reconocimiento y colaboración entre artistas y docentes, alianza que permitió el florecimiento de nuevas propuestas de enseñanza, así como formas de evaluación (Llevadot y Pagès, 2018). Mencionan además que, cuando el arte se integra en la actividad de los maestros y maestras, pone la atención en los vínculos, las relaciones y el afecto a través de compartir saberes, experiencias y lenguajes, y de la disposición para explorar nuevas posibilidades y metodologías (Llevadot y Pagès, 2018). Su propuesta iba encaminada específicamente a evaluar cómo, a través del arte, se puede elevar la calidad docente.

\section{Metodología}

El propósito de este artículo, como ya se mencionó, es describir el diseño, gestión, implementación e impacto del modelo de intervención educativo-artístico Leer para Crear, implementado en el barrio El Nejayote, Monterrey, México, de julio a septiembre de 2017, asesorado y dirigido por el proyecto AL MURAL, equipo de personas promotoras y artistas culturales que trabajan la construcción de murales con la técnica de mosaico-Trencadís.

La intervención contó con seis sesiones de taller (una sesión por semana) con duración de tres horas cada una. Cada taller atendió a más de 20 participantes, quienes se convocaron a través de llamadas telefónicas a los centros educacionales, programas de radio, televisión y espacios culturales. Se impartió un taller de lectura, un taller de mosaico-Trencadís (rama de las artes plásticas que emplea pequeños fragmentos de cerámica o 
mosaicos para crear piezas de arte) y se culminó con la inauguración de un mural realizado en una de las banquetas (aceras) del barrio El Nejayote.

Dada la naturaleza cualitativa de la investigación, se optó por un estudio de corte descriptivo que empleó el estudio de casos o análisis de casos para lograr un "acercamiento más real del contexto donde se desarrolla el fenómeno a investigar" (Jiménez y Comet, 2016, p. 2). Para ello se tomaron múltiples fuentes de evidencias que confluyeron en el análisis de datos a través de la triangulación, lo que permitió "triangular informantes/ personas, tiempos y espacios/contextos” (Rodríguez, Pozo y Gutiérrez, 2006, p.1).

Con una muestra aleatoria por conveniencia, participaron 142 sujetos, entre niñas, niños y jóvenes, además de cuatro docentes [acompañantes de los niños, niñas y jóvenes participantes], tres personas vecinas [del barrio El Nejayote] y dos personas gestoras del proyecto [artistas]. La muestra se seleccionó por la facilidad del acceso al hecho educativo-artístico y por el corto período de su ejecución.

Para llegar al objetivo de la investigación se diseñaron diferentes instrumentos que pretendían examinar sobre: a) la motivación de las y los participantes, b) el desarrollo intelectual percibido desde las competencias blandas, adquiridas o fortalecidas, las competencias duras y lenguaje plástico Trencadís; c) la práctica como solución de transformación del entorno.

Entre las técnicas de recogida de información está la observación participativa, la cual se centró en examinar la práctica de las acciones del proyecto. Los archivos como fotografía, bocetos, informe de evaluación y la recopilación de datos del acontecer educativo-artístico por las redes sociales (Facebook-Twitter-Página web) permitieron visualizar las acciones, como fueron la convocatoria y la invitación. Los registros gráficos de los talleres confirieron detalles de todo lo acontecido.

En cambio, la entrevista en profundidad, que fue aplicada luego de terminada la implementación, es considerada una "herramienta eficaz para desentrañar significaciones, las cuales fueron elaboradas por los sujetos mediante sus discursos, relatos y experiencias" (Troncoso y Amaya, 2017, p.1). Esta se dirigió a docentes, personas vecinas y gestoras del proyecto con la finalidad de describir el impacto del hecho educativoartístico en los niños, niñas jóvenes y habitantes del barrio. La información obtenida fue analizada mediante el software Atlas.ti, el cual permitió organizar, reagrupar y analizar toda la búsqueda.

\section{LeEr PARA Crear. UN ANÁLISIS DESDE SU PRÁCTICA}

\section{Historia de su surgimiento}

La propuesta educativa Leer para Crear es una iniciativa del proyecto AL MURAL, equipo de personas artistas y promotoras culturales que trabajan en conjunto en la construcción de murales con la técnica de mosaico-Trencadís. Al MURAL fue creado en marzo de 2012 por la promotora cultural Lucero Montes (líder del proyecto Caminando en Mi Barrio, y del proyecto colectivo AL MURAL desde marzo de 2012) con la finalidad de compartir la magia del arte a través de la técnica plástica antes mencionada, y así "lograr una completa expresión e integración social en diversos espacios culturales, escuelas, centros holísticos, mercados y plazas públicas" (L. Montes, comunicación personal, 12 de agosto de 2019).

Según la idea de Toro (2008), que menciona que "la escuela debe ser el espacio social en el que cada individuo puede descubrir, expresar y compartir lo mejor de sí mismo" (p.78), se le presentó a la Secretaría de Educación Pública (SEP) la idea de hacer un mural a través de la lectura. La SEP argumentó no tener el presupuesto para apoyar, en cambio, autorizó la participación del equipo AL MURAL en un evento de ecología que auspiciaban, este con el propósito que se presentó la iniciativa al personal directivo de las escuelas.

Como resultado de esta acción se registraron en el proyecto ocho planteles, entre preescolar y primaria, tanto del turno matutino como vespertino, de seis municipios del estado de Nuevo León. En todas las ocasiones, estos murales artísticos fueron ubicados en el espacio público. (Figura 1 y 2) 


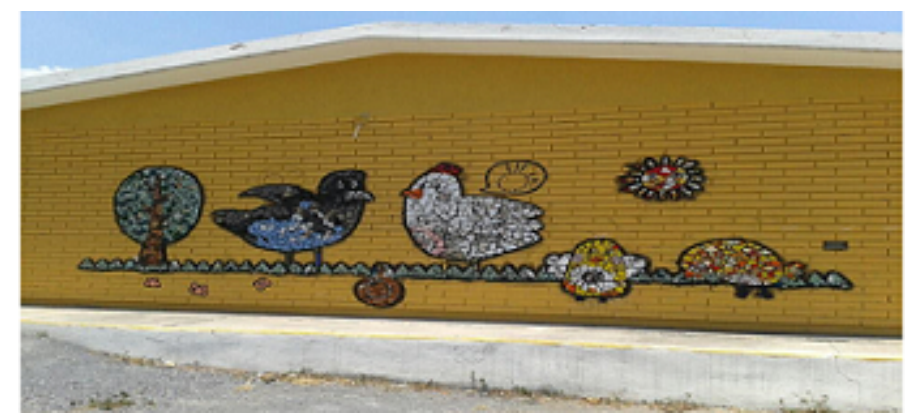

FIGURA 1.

J.N. Abraham Lincoln (Turno Matutino) en Decreto presidencial 7128 col.

Plutarco Elías Calles, Monterrey. Boceto por el artista guía Batóry Hanzo.

Fuente: Fotografía Lucero Montes, junio 2013.

La estrecha relación arte y educación en las ocho escuelas lograron fomentar la construcción de lazos en la comunidad estudiantil en pro de la sensibilidad, la inspiración y la creatividad con el uso de la lectura como un proceso mental e inspirador. Los niños, niñas y jóvenes reflexionaron sobre las habilidades que habían aprehendido al expresar sus emociones con relación a la lectura, esto en la ejecución de los bocetos y en la realización del muro con la técnica Trencadís. Se les motivó a trabajar en equipos y se incentivó el desarrollo del pensamiento creativo y crítico. $\mathrm{Al}$ respecto, una de las personas entrevistadas manifestó: "era perceptible cambios en los alumnos, lográndose un aprendizaje más significativo, motivándolos incluso a la investigación, a la lectura y a la escritura" (Maestra E2, comunicación personal, 17 de agosto, 2019). Entre las destrezas emocionales destacaron: la comunicación, el respeto por la opinión de las otras personas, el aprender a escuchar, la empatía, confianza, autoconocimiento, gratitud, urbanidad, familiaridad, y el descubrir que lo aprendido puede contribuir a engalanar y transformar el entorno.

Lo sucedido fue un "detonador para embellecer el espacio en donde no solo se estimulaba a los niños, niñas y jóvenes, sino también a los adultos que los acompañaban, quienes terminaron replicando la técnica en macetas, etc." (Lucero, comunicación personal, 12 de agosto de 2019). La Maestra E1 expone que es importante potenciar en las escuelas estas actividades en donde se combina el arte con la educación, cuya finalidad es embellecer el entorno y motivar al alumnado a través de la experiencia y el aprender-haciendo. En su caso, en los colegios que ella dirige en Monterrey, los cuales se caracterizan por poseer un entorno gris y sin emoción. Por ello, considera que acciones como estas incentivan no solo al alumnado, sino también al personal docente, además de que le ofrece al espacio educativo un lugar artístico significativo (comunicación personal, 15 de agosto, 2019). Spravkin (2013), en el Foro Nacional de Educación, menciona que "no venimos al mundo con la sensibilidad artística, sino con la capacidad para desarrollarla" (s.np).

Luego de descubrir la efectividad de esta acción educativa-artística y según lo expresado por Leeper en 1948 y 1970 (citado por Escobar, Domínguez y García, 2010), las emociones controlan la conducta, no hay error en considerar a la motivación como uno de los componentes fundamentales de todo este proceso. La idea anterior fue fundamentada por Pekrun (citado por Escobar, Domínguez y García, 2010), quien expresó que se han detectado numerosos efectos indirectos del impacto de las emociones en la motivación (p.38).

Asimismo, es imposible separar la intuición de la acción y el deseo de querer dejar una huella en un espacio que, a pesar de ser público, se asume como propio. Lucero Montes expresa que se podía notar el "orgullo de participar en una pieza artística que perdurara en el tiempo y estuviera visible a todos" (comunicación personal, 13 de agosto de 2019). 


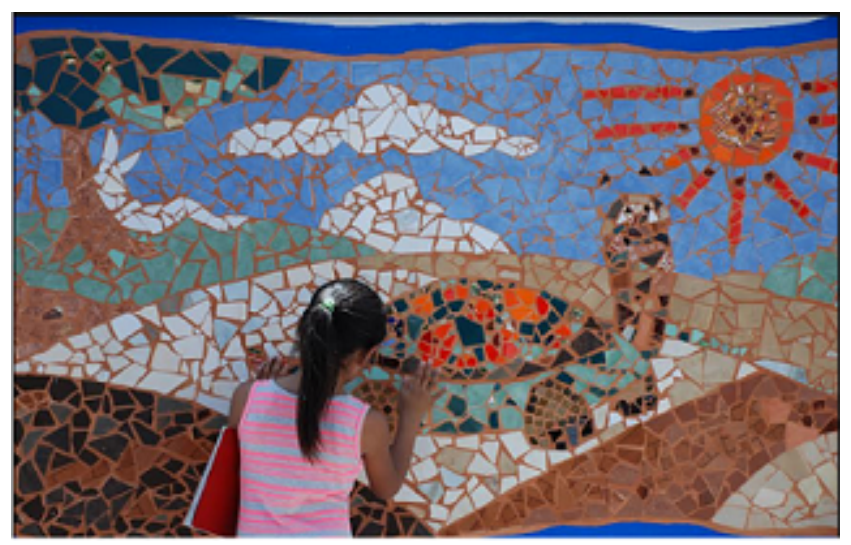

FIGURA 2.

JN. Joan Miró (Turno Vespertino) en Av. San Miguel s/n col. Alianza Real, General Escobedo. Boceto por el artista guía Carlos Limas, inspirado en el cuento 'La tortuga y la liebre'. Fuente: Fotografía Lucero Montes, junio de 2013.

La irrupción del arte en las escuelas, desde una visión diferente, rompe con la dicotomía arte-educación que se venía dando en el sector educacional en México, donde se le restaba validez e importancia al arte como medio vital para forjar identidad y consolidar una ciudadanía responsable con su entorno. Pero, obviamente, esta interpretación no es homogénea para todos, por ejemplo,

La Secretaría de Educación no apoya a los proyectos artísticos, desde sus discursos se promueve, pero en la concreta, es decir, en la vida real no es cierto, aunque estamos esperanzando de un cambio con la puesta en práctica de la Nueva Escuela Mexicana. (Maestra E1, comunicación personal, 16 de agosto, 2019).

Desde esta perspectiva, y ante los resultados obtenidos en las ocho intervenciones en las escuelas mencionadas, se decidió incursionar en otros ámbitos, como la comunidad. Es en este punto cuando surge la idea del proyecto Leer para Crear, presentado por la invitación del Programa de Apoyo a las Culturas Municipales y Comunitarias (PACMyC) convocado por la Dirección General de Culturas Populares, Indígenas y Urbanas en el año 2019 (Dirección General de Culturas Populares, Indígenas y Urbanas, 2019).

\section{Se puede cambiar el entorno en que se habita}

El arte es en sí un proceso educativo. Las disciplinas artísticas son una forma de educarse y llegar a lugares a los que solo ellas pueden llevar (Yáñez, 2012, p.259).

El proyecto educativo Leer para Crear tuvo como finalidad la intervención con un mural de mosaicoTrencadís en el espacio público por medio de la lectura. Esta fue una actividad, dirigida a niñas, niños y jóvenes, que buscaba que se expresaran de forma creativa, y con la reutilización de diversos materiales de desecho bajo el lema YO REUTILIZO, CREO Y CONSTRUYO. Su objetivo general fue fomentar el pensamiento creativo y el trabajo en equipo por medio de la lectura y la plástica en las personas participantes de los talleres y como objetivos específicos se identifican: conocer el proceso de realización de un libro, mejorar la expresión oral, elevar el nivel educativo y artístico, fortalecer el tejido social por medio de actividades culturales para el embellecimiento del entorno que integran a la comunidad y rescatan la identidad del espacio público. 


\section{REsultados PRÁCticos}

Se parte del arte como generador de un espacio para "Ser", para dialogar, para interpretar y transformar mediante el desarrollo de experiencias significativas, conformando espacios que inciten a la experimentación, al movimiento, al desarrollo de la imaginación, a la inclusión, al desarrollo de la sensorialidad atendiendo a la diversidad y jerarquizando el juego y los talleres como estrategia metodológicas privilegiadas (Ruggieri y Ternarde, 2012, p. 111).

La herramienta que se utilizó para alcanzar los objetivos propuestos fue la técnica artística de mosaicoTrencadís (que significa roto, en catalán). Se empleó el mismo proceso de intervención en los ocho centros educativos anteriormente mencionados: mural que se inspira en textos de un libro leído, se boceta y se realiza el mural con la técnica Trencadís y, por último, se coloca en el espacio público con la participación de un artista guía. "Actividad integral donde cada paso del proceso tiene una función importante y al final se ve reflejado en la pieza artística, que es vista masivamente, pieza que se apropia del espacio y se integra al mismo" (L. Montes, comunicación personal, 12 de agosto de 2019).

A continuación, se describe de forma detallada cada una de las etapas del modelo Leer para Crear que compone este estudio de caso, y se exponen los resultados obtenidos en las tres categorías propuestas para validar su impacto: motivación, desarrollo intelectual y la práctica: solución de transformación del entorno.

\section{Etapas del modelo Leer para Crear}

\section{Etapa de planificación}

Es el momento para definir espacios, escoger las lecturas, precisar los recursos, apoyos y patrocinios, planificar las acciones, delimitar número de participantes, escoger los medios de promoción más adecuado al contexto - redes sociales (Facebook, Twitter, páginas web), los medios masivos (radio, televisión), así como webflyer, Gif, vídeo, póster y volantes impresos-. En caso de coordinación con los centros educativos se precisa del contacto con su directiva, de manera tal que se avale un compromiso y responsabilidad ante el proyecto.

El proyecto Leer para Crear constó de dos talleres: un taller de lectura y un taller de mosaico-Trencadís, con seis sesiones, de tres horas una vez a la semana, para un total de 18 horas. Cada taller atendió a más de 20 participantes, en especial a niñas, niños y jóvenes, aunque también participaron personas adultas. Se trabajó de julio a septiembre de 2017 en el barrio El Nejayote, donde se emplearon los medios mencionados anteriormente para su divulgación y se contó con un resguardo fotográfico y de video de todo lo sucedido. Participó un total de 142 personas.

\section{Etapa de seducción}

En el taller de lectura se exploró el cuento de la Editorial Quiosco Oropéndola, "El Circo de las Maravillas" de Alma Morales (Escritora y miembro del grupo AL MURAL). El texto es de literatura fantástica y aborda como tema principal los valores de la tolerancia y la fraternidad.

La actividad tenía como propósito desarrollar capacidades como el pensamiento crítico, el razonamiento, la atención, la comprensión y la sensibilidad, así como desarrollar capacidades auditivas y visuales. Para ello se empleó la lectura del cuento por la autora y la representación teatral a base de títeres. Según Villalba (citado por Frías, 1996), la puesta en escena, a partir del cuento, empieza a crear, se relaciona tanto con la obra que se vuelve protagonista de ella. Jaramillo Martínez (citado por Frías, 1996) menciona que "el teatro en sí es educativo, porque en todo montaje siempre deben primar cuatro elementos: educar, concientizar, dramatizar y entretener". (p.sn). Otro componente por destacar es el vínculo pedagógico entre la triada recrear-entretener-enseñar.

En fin, la actividad se resume en la selección del cuento, la lectura de este, el acompañamiento de alguna escenificación visual o teatral, la comprensión y reflexión sobre el texto y la entrega de los libros firmados por la autora (Figura 3). Esta última acción cobra un valor significativo para la niña, el niño y la persona joven, 
pues cada libro es personalizado, "convirtiéndose en una experiencia significativa, entretenida, en un lugar de encuentro de experiencia y comunicación" (Alma Morales, comunicación personal, septiembre, 2019).

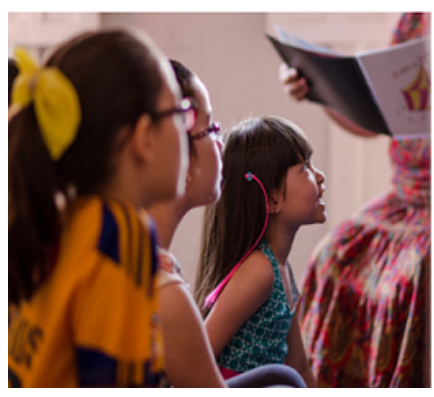

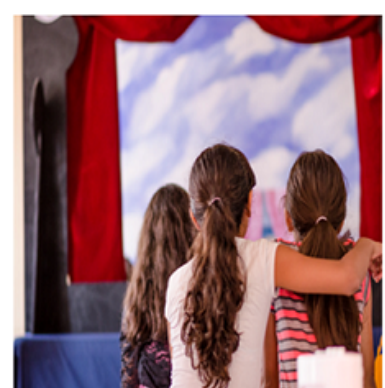

FIGURA 3.

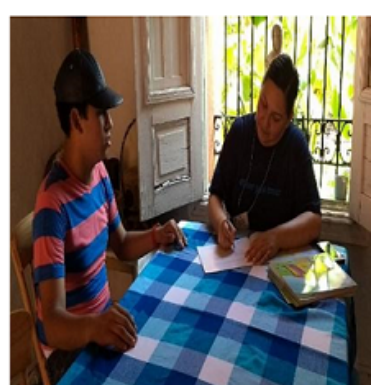

10200

Taller de Lectura en la Casa León en el barrio El Nejayote. Fuente: Fotografía Fernando Mol, septiembre 2017.

\section{Etapa de creación y/ o actuación artística}

Otro de los grandes retos de esta experiencia está relacionado con el taller de Trencadís. Se parte de la idea de que el taller de lectura buscó, además, elevar los niveles de imaginación y creatividad que se materializaron con el diseño de bocetos con relación al cuento, esto para el posterior diseño del mural. Dicha etapa se basó en la realización de bocetos individuales que luego, a través de la técnica lluvia de ideas, se evaluaron para llegar a un consenso general, el cual fue transmitido a una persona artista para que pudiera concretar la idea final.

Aprender el proceso de crear la pieza artística de Trencadís era otro de los ejercicios a realizar, se enseñó sobre las ventajas de reutilizar materiales y de qué modo podría hacerse. Luego de que la persona artista realizara su esbozo, este era presentado a los y las participantes y se comenzaba a trabajar en la banqueta, donde se plasmaba el diseño (Figura 4). La invitación a vecinos, vecinas, madres y padres de familia, y transeúntes era otra forma de crear lazos comunitarios.

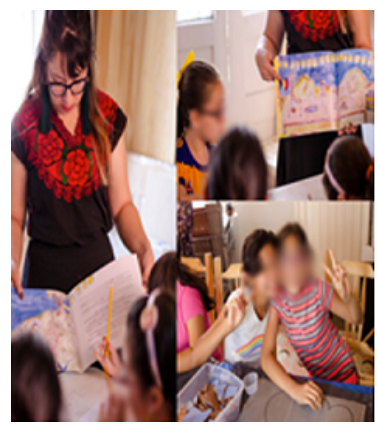

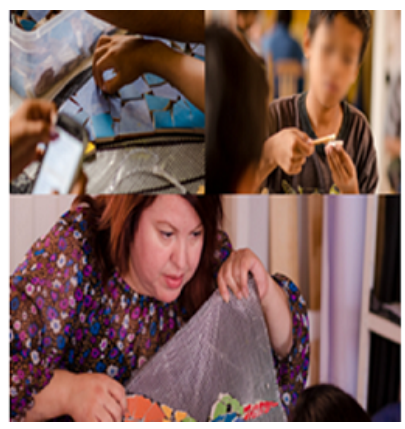

FIGURA 4.
Taller de Trencadís en la Casa León en el barrio El Nejayote.
Fuente: Fotografía Fernando Mol, septiembre 2017.

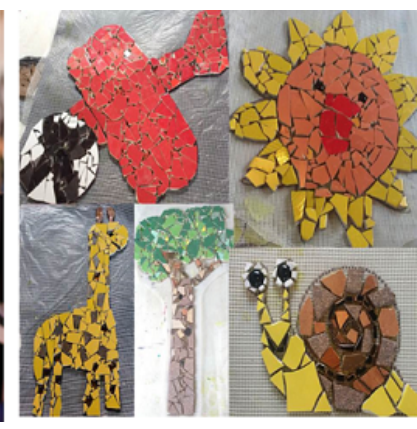
Fuente: Fotografía Fernando Mol, septiembre 2017.

El empleo de la técnica Trencadís ha sido considerado un medio idóneo de aprendizaje, es como armar un rompecabezas, incentiva la imaginación, fortifica la paciencia, disminuye el estrés, ejercita la memoria, consigue crear lazos de colaboración y de convivencia (Díaz y Ledesma, 2018). 


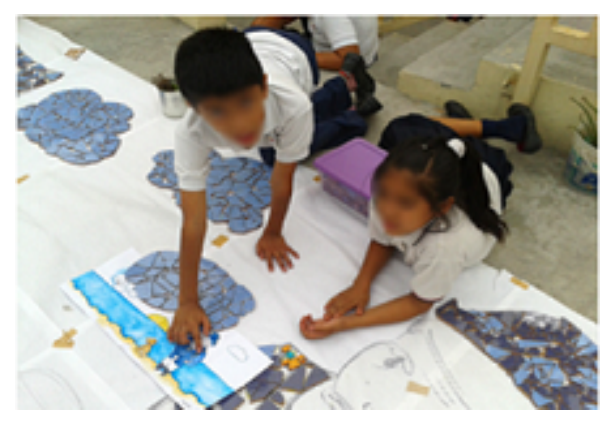

FIGURA 5.

Taller de Trencadís en la Casa León en el barrio El Nejayote.

Fuente: Fotografía Fernando Mol, septiembre 2017.

Estos momentos de creación se sintetizan en: diseñar por separado de un boceto por participante, llegar a un consenso sobre la imagen, llevar la idea a una persona artista, quien termina ofreciéndole el toque final; aprender el empleo de la técnica Trencadís, y plasmarlo en el sitio escogido, ya sea muro, banqueta, macetas, etc. (Figura 5). La etapa de la construcción y transformación, en este caso de la banqueta (acera), incentiva en cada participante el manejo de espacio y creatividad, trabajo en equipo, elevación de la autoestima, motricidad fina, coordinación ojo-mano, agilidad mental, reutilización de materiales, hacer comunidad, desarrollo de organización. El color, el volumen, la línea y, en especial, la forma, constituyen elementos cardinales de la expresión plástica. La unión de los azulejos da lugar a formas que se van colocando de manera ordenada y con sentido (Figura 6). Esto crea en las y los participantes una experiencia significativa que invita de manera natural al intercambio de ideas, el apoyo mutuo y a una identificación tanto del espacio como del medio para realizarlo.

Entre los hallazgos se pueden subrayar como competencias a desarrollar la innovación, experimentación y el auto reconocimiento. En estos espacios de creación sobresalen como elementos importantes el estímulo o motivación, el respeto a la libertad de expresión y la espontaneidad.

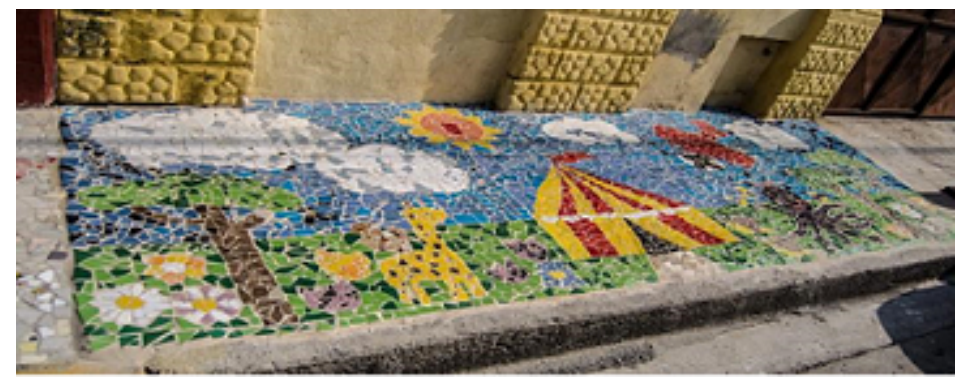

FIGURA 6.

Casa de creaciones, inspirado en el cuento del Circo de Maravillas, diseñado por Esmeralda García, septiembre de 2017, 5,88 $\mathrm{m}^{2}$. Banqueta de la propiedad que se localiza en la calle Ignacio Allende \#1225, entre Platón Sánchez y Nicolás Martínez, Barrio El Nejayote, Monterrey, N.L. Fuente: Fotografía Fernando Mol, septiembre 2017.

\section{Etapa de socialización}

"Los papeles sociales son el enlace clave entre el individuo y la sociedad" (Lucas, 1986, p.362).

Según Piaget, Mead y Cooley (citado por Lucas, 1986) "el progreso del lenguaje y de la función simbólica son básicos en el proceso de sociabilización, pues son los fundamentos de la comunicación” (p.361), según estas ideas se apoya la acción educativa que aquí se evalúa.

Muñoz (2009) reveló que la obligación de la educación social es que el ser humano se convierta en un ser activo y participativo de la sociedad en que vive. Además, expresó que el alumnado necesita comprender y entender el entorno social y los derechos y deberes que poseen ante la sociedad; aprender a respetar los 
criterios de las demás personas y "desarrollar actitudes como la participación, la tolerancia, la comprensión y la solidaridad en las relaciones (p.6), por lo tanto, la salida del entorno escolar es una vía eficaz para ofrecerles experiencias significativas.

Trabajar un mural de Trencadís desde el fomento de la lectura puede ser considerado una vía para socializar, al convertirse en un proceso que permite a las y los participantes, en primer lugar, reconocerse, respetar a las otras personas y buscar embellecer el entorno social alrededor del cual habita o estudia, y emplear materiales en desuso.

Diseñar una banqueta en un barrio, que poco a poco se ha venido recuperando de los estragos de la inseguridad de 2010, vacilación que incitó al abandono del espacio público por sus habitantes, es un tema que va más allá de su propio embellecimiento, por lo que también formó parte de la recuperación de un barrio que lucha por rescatar su vitalidad urbana y sus tradiciones con el apoyo del Colectivo Caminando en Mi Barrio (grupo multidisciplinario de personas artistas, promotoras culturales y ciudadanas radicadas en Monterrey).

Cada espacio de la ciudad, además de ser una representación de problemas de las personas de la comunidad, es una responsabilidad de sus habitantes y el arte puede ser una vía para recuperar espacios y esperanzas, ya que "a través del arte podemos rematar el horror en el que vive el país con tantos problemas de índoles sociales, de inseguridad, de drogadicción, abandono y violencia familiar sobre todo en comunidades vulnerables" (Gloria, E. Amador, comunicación personal, 12 de agosto, 2019).

Entonces, se puede asegurar, como plantea Muñoz (2009), que "el mundo del arte socializa desarrollando la creatividad, la percepción y el conocimiento del mundo interior y exterior del individuo, la expresividad ante los demás" (p.5). En fin, la etapa de socialización es aquella que se entremezcla con la etapa de seducción $y$ de creación o actuación artística. Es buscar que niños, niñas y jóvenes, a través de la exploración, la reflexión y el descubrimiento, puedan crear e intervenir en el bien de la sociedad con acciones que no solo les favorezca, sino que les permita colaborar con otras personas a no ser simplemente espectadores y espectadoras pasivas. Por medio de la diversión se aprende, se puede cambiar el espacio que circunda y crear conciencia del papel ante la sociedad.

Por último, se incluye la inauguración del mural Trencadís como la culminación de un proceso de descubrimiento, diseño y creación en comunidad que coadyuvó a ampliar las probabilidades de desarrollo personal y social de cada participante en relación con la sociedad en la que vive. La obra exhibida (Figura 6) como parte de este proyecto educativo-artístico Leer para Crear forma parte de la colección permanente del museo al aire libre que posee el barrio El Nejayote, así se convierte en una constancia de la satisfacción de haber apoyado en la recuperación del espacio público. Asimismo, deja, por mucho tiempo, un sello de aprendizaje, cooperación y reconocimiento de sus vecinas y vecinos.

\section{Conclusiones}

El artículo busca dar un bosquejo crítico de la experiencia del proyecto educativo-artístico Leer para Crear a través de la descripción y comprensión del diseño, la gestión, implementación e impacto del proyecto en el espacio público por medio del arte en el barrio El Nejayote, Monterrey, México. Por lo que se da cumplimiento al objetivo planteado.

Existen muchas metodologías de intervención artística en los centros escolares y en la propia comunidad que no han sido analizadas; esto hace que la experiencia no trascienda. El método Leer para Crear, con sus etapas de planeación, seducción, creación o actuación artística y socialización no busca registrarse como algo único y novedoso, tan solo pretende sistematizar y documentar una experiencia de intervención y reconocer el impacto que el arte y la lectura tienen en los niños, niñas y jóvenes y cómo pueden aportar a la sociedad. Se expone abiertamente que la educación tradicional no es, en estos momentos, el vehículo idóneo para instruir, sino que se precisa de una educación emprendedora, como refiere Robinson (2012b). 
Aun así, cabe responder: ¿es el arte y la lectura una vía para incentivar la participación de los niños, niñas y jóvenes en la construcción del espacio escolar y público?

La educación, al igual que el arte, deben ir alineando su mirada a la realidad circundante y convertirse en una práctica que la enfrente, en donde sus actantes se conviertan en personas motivadas, conscientes, abiertas y transformadoras del mundo real. Eisner, 2004 (citado por Checa et al. 2017) revela que las artes incentivan la imaginación de los niños y niñas, a quienes pone en contacto con los problemas circundantes y les ayuda a visualizarlos desde una diferente perspectiva.

La limitante del estudio fue que no se obtuvo ninguna información a priori con relación a las niñas, niños y jóvenes participantes, por lo que no se pudo interpretar el comportamiento y bienestar individual de manera comparativa. Sin embargo, la información obtenida, durante y después del proceso de intervención, considerando las tres dimensiones estudiadas: motivación, desarrollo intelectual (competencias blandas y duras), y la práctica con la solución de cambio del entorno, permitió comprobar que el arte y la lectura, constituyen elementos significativos para el desarrollo cognitivo y creativo de las niños, niños y jóvenes, además incentiva a la proactividad con relación a la transformación del espacio escolar y público.

Salir de los marcos del salón de clases e incursionar con el entorno, le otorga al estudiantado cierta libertad de actuación. Combinar acciones didácticas como la lectura y la plástica u otras acciones artísticas ayudan de manera directa a desarrollar su inteligencia emocional, pues incide en su conducta, motivación, emociones y valores, las denominadas competencias blandas. Asimismo, fomenta el pensamiento creativo e innovador, el trabajo en equipo, eleva su autoestima, favorece el autoreconocimiento, el respeto y la tolerancia. Como expresó Burcet (2005), "para gestionar el cambio es necesario prestar atención a las reacciones emocionales que suscita." (p.1). Además, se ha podido demostrar que permite desarrollar las competencias duras, vistas a través de la instrucción y puesta en práctica de la técnica plástica Trencadís y el compromiso por querer transformar el entorno para embellecerlo.

El vínculo arte-educación debe ser concebido como un proceso en espiral, que necesita enriquecerse continuamente, identificando logros y riesgos para evitar la incertidumbre y culminar con una acción exitosa.

Una de las importantes del estudio es que el factor motivación es la clave para un desenlace pertinente, que es importante que el niño, la niña y la persona joven aprendan jugando y descubriendo, que se les permita dilucidar abiertamente y sin prejuicios sobre cualquier tema, por lo que es imprescindible hacer gala de la triada recrear-entretener-enseñar.

Examinar, creer, imaginar, concebir, reflexionar y desarrollar también son clave para el buen desenvolvimiento social de las niñas, niños y jóvenes. Allí, inmersos en el espacio educativo, independientemente de la política educacional, deben estar docentes, artistas y promotores culturales como actantes para motivar, incentivar, transformar y comprometer al alumnado a ser cada día mejores ciudadanos y ciudadanas.

\section{RECOMENDACIONES}

A la luz de los resultados obtenidos se pueden emitir las siguientes sugerencias.

\section{Planificación:}

- Como primer factor por tener en cuenta, es imprescindible velar por el compromiso de las partes implicadas, es decir, docente-alumnado-artista y comunidad.

- Involucrar a actantes del entorno (artistas, personas escritoras, promotoras) de forma tal que se reconozca la cultura y el patrimonio de la localidad. Por lo que invitar a una persona artista o escritora 
del territorio, ya sea de manera presencial o virtual, les ofrece a las niñas, y jóvenes el reconocimiento hacia lo local, de esta forma se fortalece su identidad.

- Definir con anterioridad a su implementación las competencias y habilidades a desarrollar o fomentar.

- Planificar los tiempos de las etapas del modelo Leer para Crear antes de iniciar la intervención: planificación, seducción, creación o actuación artística y de socialización, así como los procesos de reflexión.

- En caso de implementarse desde la academia, se debe evitar rúbricas que frenen la creatividad. Es preciso, dar libertad de pensamiento, diseño y ejecución.

- Definir con inmediatez los recursos a emplear. En especial estimular el reciclaje para contribuir al cuidado del medio ambiente, desde el criterio de que en lo roto también existe belleza, una belleza que puede convertirse en un objeto de utilidad, que consigue perdurar en el tiempo como lo es la creación de una banqueta (acera), bancos, macetas o muros.

- Es imprescindible medir (evaluar) un antes y un después, de manera tal que se pueda comprobar un cambio de comportamiento, actitud y de habilidades de las y los participantes.

\section{Seducción, creación o actuación artística y de socialización:}

- El modelo Leer para Crear se centra tanto en la lectura como en la plástica (mosaico-Trencadís) y desarrolla acciones de teatro, música e incluso gastronomía. No necesariamente tiene que ser la plástica, se pueden generar otras acciones artísticas-culturales que, en conjunto con la lectura, puedan transformar el entorno, recuperar tradiciones, reconocer el talento local, cuidar el patrimonio y apuntalar los conocimientos de historia u otra materia.

- Incitar, por medio de la lectura, a explorar y entender el entorno y a la toma de decisiones.

- Potenciar, a través de lo lúdico, la exploración, el descubrimiento, la creatividad y la invención.

- Considerar las etapas del proyecto no como un maratón de actividades a desplegar, sino como espacios de escucha, diálogo y reflexión.

- Para la aplicación de la técnica plástica del mosaico-Trencadís, se proponen los siguientes pasos: a) se selecciona el tema de la obra plástica a crear (usar como eje temático la lectura escogida), b) cada integrante de la actividad debe diseñar su propia propuesta de diseño (partir de su reflexión con relación a la lectura), c) a través de la lluvia de ideas crear entre todas las personas participantes un diseño único, sería valioso el contar con el apoyo y asesoría de una persona artista plástica, d) elegir colores y material a utilizar (es importante incitar al reciclaje, es decir, al uso de materiales en desuso, platos, tazas, vasos, frascos, botellas y mosaicos rotos), e) cortar las piezas de mosaicos en pequeños pedazos con un martillo (usar lentes y cubrir los azulejos con una manta), y luego separarlos por color, f) pintar en una malla el diseño del boceto artístico, solo escoger sus contornos, se debe tener presente sus dimensiones con relación a la superficie a intervenir, g) colocar y pegar las piezas en la malla de acuerdo al diseño (emplear pegamento), h) preparar el espacio donde se ubicaría la pieza de Trencadís (muro, banqueta (acera)), es decir, velar porque la superficie esté limpia, i) colocar la pieza en la superficie elegida con cemento crew, $\mathrm{j}$ ) por último, emboquillar la superficie con la finalidad de darle el acabado final. Se sugiere, además, crear una cédula descriptiva o una firma con la fecha junto a la pieza o dentro de ella; estas piezas perduran en el tiempo, por lo que necesitan estar identificadas. Recursos por emplear: hojas y colores para plasmar el diseño; martillo y pinzas para romper y cortar los mosaicos u otro material; malla, pegamento, cemento crew y guantes para el emboquillado.

- Con relación a las lecturas, como se ha explicado, se puede escoger de las seleccionadas en el programa de estudio de la escuela u otra. No obstante, se pone a su disposición, con la autorización de su autora, la lectura empleada en esta experiencia. De tener interés en el cuento con fines de replicar el proyecto, 
por favor escribir a quioscoropendola@gmail.com y con gusto su autora Alma Morales les enviará el e-book.

- Por último, y como un elemento importante a destacar, se les invita a todas las partes implicadas a la inauguración de la pieza de mosaico Trencadís, obra de teatro o exposición plástica, es decir, a aquella acción artística-cultural que se considere la más adecuada al contexto y a los recursos. Lo recomendable es que se termine con una gran fiesta artístico-cultural. Socializar lo creado es una forma de darlo a conocer, identificar su impacto, y, sobre todo, permite visualizar la apreciación de las personas participantes, acompañantes, invitadas, etc.

\section{AgRADECIMIENTOS}

Al Grupo AL MURAL por la oportunidad de conocer el mundo del arte e irrumpir en el proceso de diseño, gestión, ejecución del proyecto educativo Leer para Crear; a Lucero Montes y Alma Morales como miembros del proyecto. A la Mtra. Gloria E. Amador y la Mtra. Daniela Olmos por su entrega y dedicación al trabajo con los niños y niñas; a las vecinas y vecinos del barrio El Nejayote, Monterrey. A las niñas, niños y jóvenes participantes en la experiencia, quienes desmitifican la noción y visión de lo que el arte-educación puede aportar en el desarrollo creativo y social inclusivo. En fin, todas aquellas personas que colaboraron con el trabajo y que fueron portadores de sus experiencias y aprendizajes.

Este artículo busca resguardar y reconocer la labor artística y académica de Lucero Montes. En Paz descanse.

Planteles intervenidos 1. J.N. ROSARIO CASTELLANOS (Turno Matutino en Monterrey); 2. J.N. ABRAHAM LINCOLN (Turno Matutino en Monterrey)); 3.J.N. HERNÁN CORTÉS (Turno Vespertino en Apodaca); 4. PRIM. PROFR. HELIODORO RUÍZ CASTILLO (Turno Matutino en Santa Catarina); 5. J.N JORGE RANGEL GUERRA (Turno Matutino en García); 6. PRIM. CHAPULTEPEC (Turno Matutino en San Nicolás de los Garza); 7. J.N. JOAN MIRÓ (Turno Vespertino en General Escobedo); 8. PRIM. FRANCISCO G. SADA (Turno Matutino en San Nicolás de los Garza).

\section{REFERENCIAS BIBLIOGRÁfiCAS}

Abad, J. (2012). Propuesta de Arte comunitario en contextos escolares. En: E. Carpio (Coord.). Formas de expresión y creaciones propias. La competencia cultural y artística (pp. 5-44). España: Ministerio de Educación, Cultura y Deporte.

Berdejo, C. y Urbina, S. (Coords.). (2018). Arte. Guardián de memoria. (1 ed.). Guadalajara, Jalisco, México: Universidad de Guadalajara.

Burcet, J. (2005). Gestionar el cambio es gestionar emociones. Recuperado de https://gestiondelcambio.com.es/gestion ar-el-cambio-es-gestionar-emociones/

Cabrera, R. I. y Gallardo, L. (2013). Educación intercultural del estudiante universitario: el enfoque de formación humanístico intercultural. Revista Electrónica Actualidades Investigativas en Educación, 13(3), 1-34. Recuperado de http://www.redalyc.org/pdf/447/44729878002.pdf

Checa, R., Díaz, V., Guzmán, L. y Olaya, M. (2017). El cerebro infantil necesita arte: Joaquín Lobato, pintor y poeta. Documentación. Consejería de Educación. Junta de Andalucía. Dirección general de innovación. Recuperado de https://bit.ly/33eIE97

Consejo Nacional de la Cultura y las Artes. (2016). Por qué enseñar arte y cómo hacerlo. Caja de herramientas para la educación artística. Santiago, Chile: Ograma impresores.

Cros, S., Forasté, A. y Masgrau, M. (2015). Creatividad. La empresa de tu vida. Barcelona: Plataforma Editorial.

Díaz, A. y Ledesma, R. (2018). Un barrio de color: el diseño de un museo al aire libre mediante trecandís en El Nejayote. Panambi, (6), 55-74. doi: https://doi.org/10.22370/panambi.0.6.1137 
Díaz, A.Y., Figueroa, S., Bigurra, R. y Fontecilla, H.O. (2020). El arte como herramienta para desarrollar la creatividad: una experiencia en un taller de expresión libre. Enseñanza e Investigación en Psicología, 2 (2), 270-277.

Dirección General de Culturas Populares, Indígenas y Urbanas. (2019). Programa de Apoyo a las Culturas Municipales y Comunitarias (PACMC). México: Gobierno de México. Recuperado de https://bit.ly/2RaVZK5

Eisner, E.W. (1987) Procesos cognitivos y curriculum. Barcelona: Martínez Roca.

Eisner, E. W. (1972). Educar la visión artística. Barcelona: Paidós.

Efland, D. y Stuhr, P. (2003). La educación en el arte posmoderno. Barcelona: Paidós.

Elisondo, R., Donolo, D., Rinaudo, M.C. (2012, 7 de febrero). Espacios comunitarios cotidianos. El arte como oportunidad para ser, crear y transformar. Arte y sociedad. Revista de investigación, (1). Recuperado de http:// asri.eumed.net/1/edr.html

Escobar, J.G., Domínguez, A.A., y García, R. (2010). La expresión emocional en el aula y su relación con el aprendizaje significativo: estudio cualitativo en alumnos de la licenciatura en psicología de la UAEH. Revista Cientifica Electrónica de Psicologia, (10). Recuperado de https://www.uaeh.edu.mx/investigacion/icsa/LI_ProcCogn/Jor ge_Torres/9.pdf

Fernández, T. G. (2010). Tres posibles sentidos del arte en la escuela. Revista Iberoamericana de Educación, (52), 23-41. Recuperado de https://rieoei.org/historico/documentos/rie52a01.pdf.

Frías, R. A. (29 de marzo de 1996). El aporte del teatro al aula [Publicación de blog]. Recuperado de https://www.el tiempo.com/archivo/documento/MAM-328766.

García, M. C. (2012). ¿Qué puede aportar el arte a la educación? el arte como estrategia para una educación inclusiva. Arte y sociedad. Revista de investigación, (1). Recuperado de http://asri.eumed.net/1/cgm.html

Gadamer, H.C. (1998). Texto e interpretación. Recuperado de https://repositorio.uam.es/bitstream/handle/10486/2 83/22150_Texto\%20e\%20interpretaci\%F3n.pdf?sequence=1

Gardner, H. (1994). Educación artística y desarrollo humano. Barcelona: Paidós.

Gemma, C. (2017). Evaluación Proyecto Planters. Girona, España: ConArte Internacional. Recuperado de https://n 9.cl/dz6t

Gerver, R. (2010). Crear hoy la escuela del mañana. La educación y el futuro de nuestros hijos. Madrid: Ediciones SM.

Giráldez, A., y Pimentel, L. (Coords.) (2009). Educación artística, cultura y ciudadanía De la teoría a la práctica (pp. 5-135). Madrid: Organización de Estados Iberoamericanos para la Educación, la Ciencia y la Cultura (OEI). Recuperado de https://n9.cl/8t62

González, C. B. (2012). La función del arte en la educación. Pensamiento palabra y obra, (87), 56-78. Doi: https://d oi.org/10.17227/ppo.num8-1744

HART, L. (1983). Human Brain, Human Learning. New York: Longman.

Jiménez, C.G. (2011). La importancia de la educación artística en la formación integral del alumno. Campeche, México: Universidad Pedagógica Nacional.

Jiménez, V. y Comet, C. (2016). Los estudios de casos como enfoque metodológico. Revista de Investigación en Ciencias Sociales y Humanidades, 3(2), 1-11. Recuperado a partir de https://revistacientifica.uamericana.edu.py/index.p $\mathrm{hp} /$ academo/article/view/54

Kerlan, A. (2007). L'art pour éduquer. La dimensión esthétique dans le projet de formation postmoderne. Education et sociétés, 19, 83-97.

Llevadot, M., y Pagès, A. (2018). Los proyectos de integración del arte en educación (arts integration) y la mejora de la calidad docente a través de un estudio de caso. Revista Iberoamericana De Educación, 77(1), 121-140. https:/ /doi.org/https://doi.org/10.35362/rie7713093

Lucas, M. A. (1986, julio-septiembre). El proceso de socialización: un enfoque sociológico. Revista Española de pedagogía. 173. Recuperado de https://bit.ly/3igojH0

Marchesi, Á. (2009). Las Metas Educativas 2021. Un proyecto iberoamericano para transformar la educación en la década de los bicentenarios. Revista Iberoamericana de Ciencia, Tecnología y Sociedad - CTS, 4(12), 87-157. Recuperado de https://www.redalyc.org/articulo.oa?id=924/92411770007 
Muñoz, J. M. (2009). La importancia de la socialización en la educación actual. Revista Innovación y experiencias educativas, 14. Recuperado de https://bit.ly/35npEs0

Pagès, A. (2011). Temps de transmissió. Les seves vicissituds avui. Lleida. Espanya: Pagès editors

Palacios, L. (2006). El valor del arte en el proceso educativo. REencuentro. Análisis de Problemas Universitarios, (46), 1-21. Recuperado de https://www.redalyc.org/pdf/340/34004607.pdf

Robinson, K. (2012a). Busca tu elemento, Aprende a ser creativo y desarrollaras tu potencial. México: Urano.

Robinson, K. (2012b). El elemento. México: Urano.

Rodríguez, C., Pozo, T., Gutiérrez, J. (2006). La triangulación analítica como recurso para la validación de estudios de encuesta recurrentes e investigaciones de réplica en Educación Superior. RELIEVE, 12(2), 73-88. doi: https:// dx.doi.org/10.12795/pixelbit.2015.i47.05

Ruggieri, C. y Ternarde, M.R. (2012). Proyecto de la Inspección Nacional de educación inicial: Habitat-Arte: Diálogos con el entorno. En El papel del arte en los procesos educativos. 1ª Bienal de Educación Artística (pp. 259-262).Uruguay: Ministerio de Educación y Cultura. Recuperado de https://issuu.com/antoniopenabibliot eca/docs/libro_bienal/104

Sánchez, S. M. (2010). Arte y educación: diálogos y antagonismos. Revista Iberoamericana de Educación, (52), 43-60.

Santodomingo, R. (2019, 9 de julio). La escuela se tiene que desescolarizar a si misma [Web log post]. Recuperado de https://bit.ly/2Qmzchc

Sañudo, L. y Ademar, H. (Coords.). (2019). Miradas y voces de la Investigación Educativa II: Curriculum y Diversidad. Innovación educativa con miras a la justicia social. Aportes desde la investigación educativa. (1a ed.). Córdoba: Comunic-Arte; Universidad Católica de Córdoba. Facultad de Educación. Recuperado de http://pa.bibdigital .uccor.edu.ar/2495/1/L_Sa\%C3\%B1udo_Ferreyra.pdf\#page=146

Spravkin, M. (junio, 2013). Artes plásticas en el preescolar: cuestiones del enseñar y del aprender. XXVIII Foro Nacional de Educación Preescolar. Ponencia llevada a cabo en Morelia, Michoacán. Recuperado de https://goo.gl/Cex0zk

Subsecretaría de Educación Básica (2019). Modelo educativo: nueva escuela mexicana. Recuperado de https://bit.ly/ $2 \mathrm{QSuVPu}$

Toro, J. (2008). La creatividad del “co-razón”. Revista Creatividad y Sociedad, 15(12), 77- 96.

Troncoso, A. C. y Amaya, A.P. (2017). Entrevista: guía práctica para la recolección de datos cualitativos en investigación de salud. Revista de la Facultad de Medicina, 65 (2), 329-332. Recuperado de https://doi.org/10 $.15446 /$ revfacmed.v65n2.60235

Yáñez, F. (2012). El papel del arte en los procesos educativos.1 1a Bienal de Educación Artística (pp. 259-262). Uruguay: Ministerio de Educación y Cultura.Recuperado de https://issuu.com/antoniopenabiblioteca/docs/libro_biena $1 / 104$

\section{INFORMACIÓN ADICIONAL}

Cómo citar: Díaz Fernández, A. y Ledesma Gómez, R.D.G. (2021). El arte y la creatividad en niños y jóvenes: procesos de transformación del espacio escolar y público. Revista Educación, 45(2). Recuperado de http:// doi.org/10.15517/revedu.v45i1.43550 